\title{
Collaborative outreach
}

Lydia Sanmarti-Vila, Marta García-Matos, Federica Beduini, Silvia Carrasco

Lydia Sanmarti-Vila, Marta García-Matos, Federica Beduini, Silvia Carrasco, "Collaborative outreach," Proc. SPIE 9946, Optics Education and Outreach IV, 99460I (27 September 2016); doi: 10.1117/12.2236303

SPIE Event: SPIE Optical Engineering + Applications, 2016, San Diego, California, United States 


\title{
Collaborative Outreach
}

\author{
Lydia Sanmarti-Vila, ${ }^{* a}$ Marta García-Matos, ${ }^{a}$ Federica Beduini ${ }^{a}$ and Silvia Carrasco ${ }^{\mathrm{a}}$ \\ ${ }^{\mathrm{a}}$ ICFO-Institut de Ciències Fotòniques, The Barcelona Institute of Science and Technology, 08860 \\ Castelldefels (Barcelona), Spain
}

\begin{abstract}
Many research projects and scientific initiatives multiple their impact and relevance through collaborations. It is the contact and exchange with others that often brings a scientist's work to the next level. The same happens with outreach: sharing activities, concepts, materials and knowhow may lead to greater impact, more innovative, inspirational ideas with enough potential to create pioneering outreach activities.

A good example for this is the FP7 European project "GoPhoton!", an initiative of ECOP (European Centres of Outreach in Photonics) that ran through 2014 and 2015 and finished at the beginning of 2016 and was directed at the general public, young minds as well as current and future entrepreneurs. This project was based on the idea of sharing activities which is at the core of ECOP's identity- already existing in other nodes (institutions within the project), or created within GoPhoton! The main concept was the effective leverage of local links such as the networks of educators and professionals in general, industrial clusters, museums, universities, governmental and non-governmental organizations, all from a Pan-European perspective possible through ECOP. This has resulted in over 200 events impacting over two million people. The sharing of activities across institutions that have different resources, facilities, and cultural environments is not straightforward. One of the biggest challenges for the consortium was to be able to extract the concept and identity of each activity, so that it could be realistically adapted to each local context. A crucial point was being able to effectively use the knowhow gained from a partner's activity, in a way that the essence of the activity remained untainted across the participating nodes, while still triggering innovation locally.
\end{abstract}

Keywords: Activities, ECOP, GoPhoton, outreach, IYL2015, European project, international collaboration, impact

\section{INTRODUCTION}

The importance of Photonics as an enabling technology that drives growth in many major markets such as healthcare/ life sciences, energy, communications, manufacturing, or art/culture is recognized by many organizations. The proclamation by the United Nations Organization of 2015 as the International Year of Light and Light-based Technologies ${ }^{1}$ was further evidence of this. Beyond the intangible value that Photonics has for society's wellbeing, the world market of Photonics will reach 615 Billion Euros in $2020^{2}$. In order to sustain this progression, the market needs to ensure engagement of the younger generations in STEM (Science, Technology, Engineering and Mathematics) to allow the development of a competitive work-force of well-trained young photonics professionals in an environment that promotes entrepreneurship and attracts investment. All this is partially promoted through targeted outreach activities. Outreach is understood as those activities that bring Photonics closer to society, e.g. schools, universities, scientists, industry, general public, museums, artists, etc. Many photonics research institutions perform outreach activities with a certain frequency. Some have a dedicated workforce, while others have investigators that partially dedicate a proportion of their time to it.

Outreach is an activity that is increasing in importance within many research organizations, and we can only expect that this role will become more prominent as outreach activities have proven to be a helpful support in meeting the demands for a larger and better prepared workforce as well as in promoting entrepreneurship and innovation. While outreach is a matter for all photonics stakeholders -scientists, students, educators, industry members, entrepreneurs, investors, media

Optics Education and Outreach IV, edited by G. Groot Gregory, Proc. of SPIE Vol. 9946, 99460I

(C) 2016 SPIE · CCC code: 0277-786X/16/\$18 - doi: 10.1117/12.2236303 
and the general public- individual research organizations, whose primary goal is not outreach but to do research and innovation, are often the drivers of photonics outreach programs, especially those directed to the general public and students. Despite this, research organizations often lack sufficient human and financial resources to be dedicated to outreach, and thus it is important to find ways to maximize the available resources and to focus them on what is most effective.

While many research projects and scientific initiatives multiply their impact and relevance through collaborations, outreach activity is often carried out individually by institutions. The belief that it is the contact and exchange with others that often brings a scientist's work to the next level could also be applied to outreach: sharing activities, concepts, materials and knowhow may lead to greater impact, more innovative, inspirational ideas with enough potential to create pioneering outreach activities, especially in a context of limited resources.

\section{BUILDING LONG-LASTING ALLIANCES TO COLLABORATE IN OUTREACH PROJECTS}

\subsection{ECOP, an alliance linked to several projects}

Following the idea that there was a need for a strong cooperation in photonics outreach that would enable ongoing and sustainable collaborations in this filed, ICFO proposed and lead a group of European centers with leading photonics research and committed to outreach in Photonics, to team up in an alliance, leading to ECOP. The member centers all had in common the fact that they did research in photonics, were committed to do outreach in this field, and furthermore, were passionate about it. The idea behind this alliance was to have a structure in place that would allow an exchange of knowhow, the sharing of materials, and allow the members to build consortiums that can apply together for international funds, knowing that the alliance would provide stability and sustainability to the projects. The idea was that ECOP members would team up to create and share outreach ideas, content and materials, all developed under a Pan-European dimension. Members would then implement the outreach activities locally, leveraging the networks, reaching out to all segments of society and further enriching the outreach activities through these local collaborations. This is how ECOP, which is currently still chaired by Prof. Lluis Torner, founder of the alliance, was formally created in 2012.

ECOP is a long-standing partnership of European research and innovation centers passionate about the underlying areas of photonics in particular and STEM in general, and are committed to having young people, multidisciplinary professionals, entrepreneurs and society at large, discover the potential and wonders of photonics, its impact in our daily life and the opportunities it offers professionally and to industry. In addition, the alliance includes members of wide European networks, such as LaserLab and the Nanophotonics Europe Association. Current members are located across Europe, providing the alliance a Pan-European vision. The distribution of their management Board can be seen in Figure 1. 


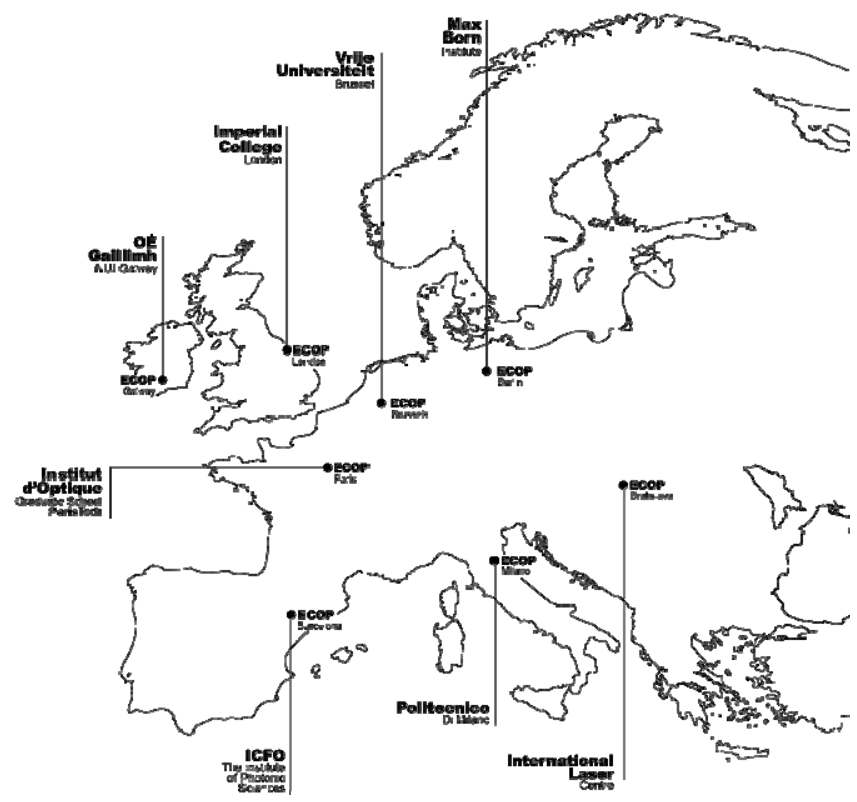

Figure 1: ECOP's Board members

ECOP has several outreach initiatives, such as the European project GoPhoton! ${ }^{3}$, a Pan-European outreach project coordinated by ICFO that aims at bringing Photonics, and Photonics-related careers (e.g. STEM careers) closer to society, and the LIGHT2015 project $^{4}$, another outreach European project in celebration of the international Year of Light 2015 (IYL2015) led by the European Physics Society (EPS). In addition to these projects, ECOP is constantly preparing additional initiatives that help increase the visibility and the integration of the field across all segments of society.

\subsection{GoPhoton!, an ECOP initiative based on collaborative outreach}

GoPhoton!, a project that started at the beginning of 2014 and lasting for 26 months, was based on the concept of sharing knowhow, pulling the partner's expertise on photonics outreach together, and replicating activities across Europe through the ECOP network. This project aimed to make a significant contribution to raising awareness about the importance of Photonics, aiming at having impact on young minds, entrepreneurs and society as a whole. GoPhoton! aimed at transmitting a critical message across Europe: Photonics is ubiquitous and pervasive, it is a key enabler of the European economy and job creation, and it offers outstanding career and business opportunities. The project addressed these challenges through a series of actions that were developed with a collaborative approach.

The consortium was composed of ICFO (coordinator), FBH, VUB, IC, POLIMI, IOTA, NUIG and ILC, all ECOP members or affiliated with ECOP members (see Table 1). It spanned two years, with 2014 dedicated to defining the activities, creating materials and content, and planning the Photonic Splashes (periods of high intensity of photonics outreach activities), while 2015 was dedicated to implementing the activities. Monitoring of previously defined key performance indicators was done throughout the entire project. Furthermore, GoPhoton! strongly involved relevant 
European stakeholders, seeking synergies with Photonics21, industrial clusters and educational networks, and the International Year of Light in 2015 as well as other EU funded photonics outreach projects.

\begin{tabular}{|c|c|c|}
\hline ICFO' & ICFO (Coordinator) & Barcelona \\
\hline $\begin{array}{l}\text { Imperial College } \\
\text { London }\end{array}$ & Impcrial Collage & London \\
\hline 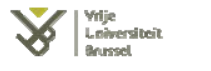 & Vrije Universiteit Brussel Erasmus & Brussels \\
\hline 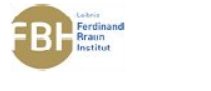 & $\begin{array}{l}\text { Ferdinand-Braun-Institut; Lcibniz-Institut für } \\
\text { Höchstfrequenztechnik }\end{array}$ & Berlin \\
\hline 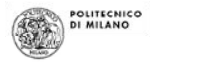 & Politcenico di Milano & Milan \\
\hline marrid & Institut dOptique & Paris \\
\hline 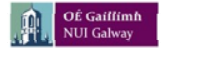 & National University of Ireland & Galway \\
\hline Loser $(O)$ Cenlro & International Laser Centre & Bratislava \\
\hline
\end{tabular}

The GoPhoton! activities happened in Photonics Splashes, periods of intense photonics outreach activity that included all type of activities and that happen throughout the participating nodes. These actions aimed to emphasize different aspects of Photonics in a way that each one addressed a different set of audiences. During the design phase partners designed their Photonic Splashes, which were improved and augmented based on the learning from prior Photonic Splashes as well as from local initiatives compatible with the GoPhoton! events. As seen in Table 2, the array of activities was significantly broad.

\begin{tabular}{|l|l|}
\hline Main activities & GoPhoton! activities \\
\hline \\
Big, highly visible events that have been used to open \\
Photonic Splashes or bring visibility to the Photonic Splashes.
\end{tabular} \begin{tabular}{l}
$\begin{array}{l}\text { Photonics Apps: NUI developed two open-code applications } \\
\text { for smartphones that have been used extensively in different } \\
\text { and different workshops. }\end{array}$ \\
\hline
\end{tabular}




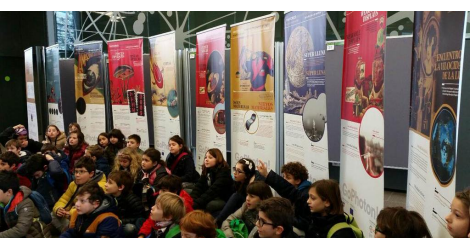

A Photonics Exhibition that was created by ICFO in English and translated into local languages and printed by the partners and that has been exposed across Europe; it is currently available at GoPhoton!'s website.

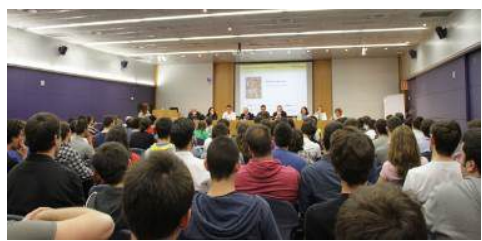

LIGHTtalks: a series of TEDx-like events with inspirationa talks targeting different audiences that were conceptualized by ICFO and have been replicated beyond GoPhoton! thru the LIGHT2015 project.

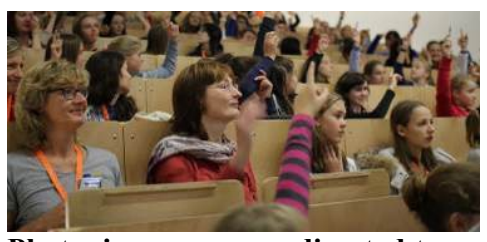

Photonics congresses directed to young people (Girls, Boys \& Photonics): This activity combining theory workshops and hands on experiments for young students, aimed at addressing the problem of under-representation of girls in careers related to Photonics. It was built on the previous experience acquired by the FBH team through a successful program held in the Berlin area for several years in STEM $^{5}$.

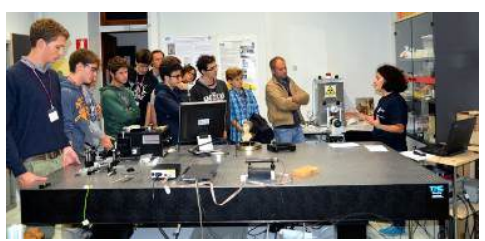

Open Days: Partners opened their facilities' doors to general public and other audiences to bring photonics, and research and innovation in Photonics closer to society.

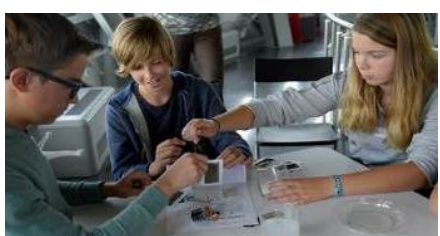

Photonics Toolkits: VUB has developed a collection of hands-on experiments organized in toolkits composed of different modules targeting young minds, high-achieving, gifted and talented youngsters, and the industry. Partners have translated the manuals into the local languages and have tested the different modules and collected feedback.

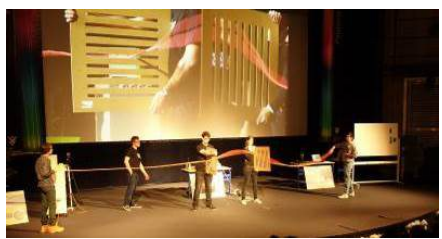

Photonics show: VUB developed a Photonics Show that teaches young minds about the properties of light in a fun and interactive way ${ }^{6}$. This concept around this activity has been replicated in other nodes.

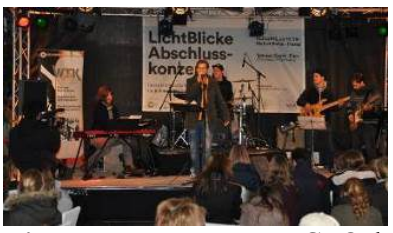

Light on the waves: ICFO has held several editions of this contest that mixes literature, music and science and is directed at schools and general public. ICFO has worked with ECOP partners to help them adapt this contest to a German and an English editions ${ }^{7,8}$.

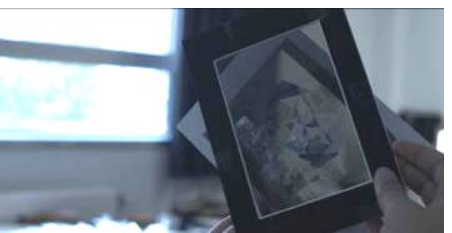

Polarization art: this activity was created within GoPhoton! by the Imperial College team, and it has been replicated by other nodes that have integrated this activity in their hands on activities program. This activity uses art to explain light polarization, allowing participants, mainly young minds, to make artistic creations that change as they are seen through polarized filters in different positions. 


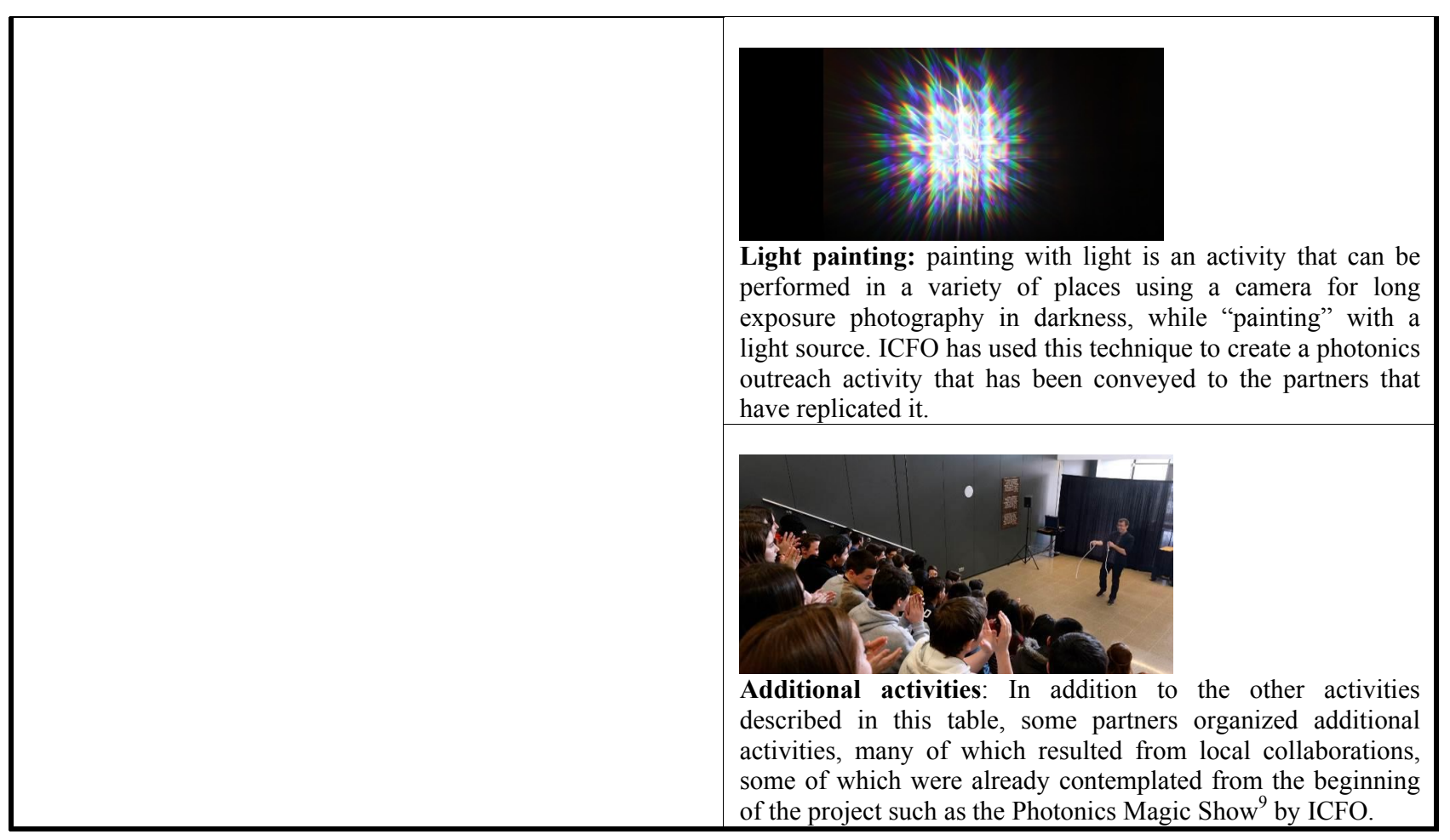

Table 2: GoPhoton! activities

These activities were either created within GoPhoton! by one of the partners or were already existing at one of the nodes. As shown in Figure 2, ECOP put in place a mechanism to transfer the knowhow between the originators or creators of the activity, and the replicators. This mechanism integrated different elements. The first was to create profiles or guidelines for the activities, which all followed the same structure for easy use. These profiles would include all the necessary information for a partner to replicate another partner's activity. Replication is a challenge, since the implementation conditions are not the same across partners. The way that GoPhoton! approached this was by creating activity profiles that would clearly establish the cornerstones of the activities that had to be respected when replication occurred. These cornerstones included the concept, the objectives, the overarching message and structure of the event. In addition, the profiles would include information on type of costs, needed technical support, timings and other useful information to be taken into consideration when preparing the activity in other nodes. These profiles enabled the partners to implement the activity honoring the concepts and event identity while adapting them to their facilities, human resources and particular context. 


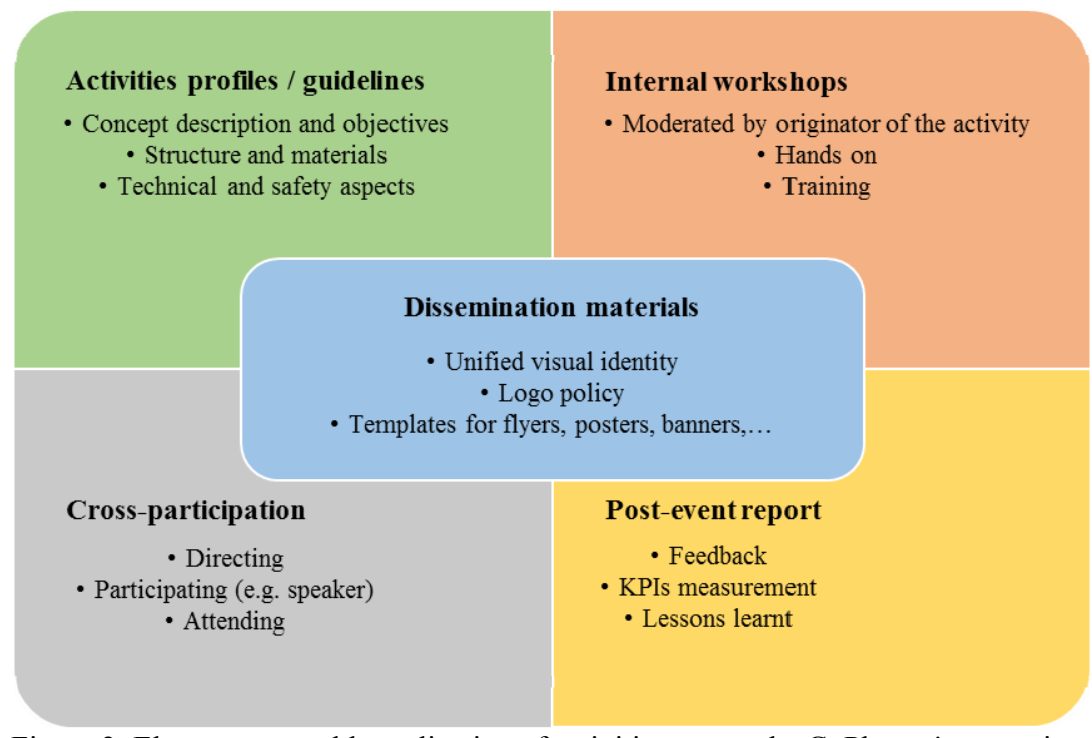

Figure 2: Elements to enable replication of activities across the GoPhoton! consortium

Once the guidelines were created, another important element that GoPhoton! put into place was the creation of internal workshops through which the activity originator would train the other partners. These were hands-on knowledge transfer workshops that would enable the replicators to test core components of the activities to be replicated.

A valuable component of the mechanism was the active role that partners took in other partners' activities. This crossparticipation enabled the application of the knowhow learnt through the guidelines and the workshops in different settings, and increased the lessons learnt around the activities by the participating partners. Once activities were implemented at the different nodes, partners collected feedback and measured the key performance indicators established within GoPhoton!, and reported back to the rest of the consortium. The report included lessons learnt, which greatly contributed to growing the group's knowhow and to the enhancement of subsequent activities.

\subsection{Reaching out to other programs, locally and internationally}

The collaborative approach that ECOP takes, goes beyond the alliance, since it is applied in other international projects as well as local initiatives. Some examples are the involvement of the ECOP members in the national committees of the International Year of Light 2015 initiative, as well as other European projects. A good example of this leverage has been the participation in the European Horizon 2020 project LIGHT2015, which has led to the replication of GoPhoton! activities, specifically LIGHTtalks, in 19 countries across Europe. This is a good illustration of how the European photonics outreach community can benefit from collaborating and how it has been able to hold activities using the guidelines that were developed within GoPhoton! to implement the events.

This project has also provided the opportunity to strengthen the local collaborations. Local collaborations have proven to be important for the success of innovative outreach activities that take science and technology out of the research organizations, closer to the general public, and that use multidisciplinary tools to engage society. It is worthy to point out that the fact that 2015 was declared the International Year of Light and Light-based Technologies enabled many outreach collaborations with many local institutions and communities such as museums, educators, artists, local governments, etc. For instance, thanks to these local collaborations, ICFO has been able to work with British artist Andrew Chappel ${ }^{10,11}$ to develop a light installation that was exposed in 2015 within Barcelona's light festival LlumBCN ${ }^{12,13}$, or was able to organize a citizens science experiment within the LIGHT2015 ${ }^{14,15}$ project that required the collaboration from local 
schools, research institutions, Barcelona's city council, and civil organizations, as well as of course, the citizens of Barcelona. This fact has allowed the establishment of a working relationship with organizations and professionals that has continued beyond 2015 and will be leveraged in current and future outreach activities potentially leading to more innovative events.
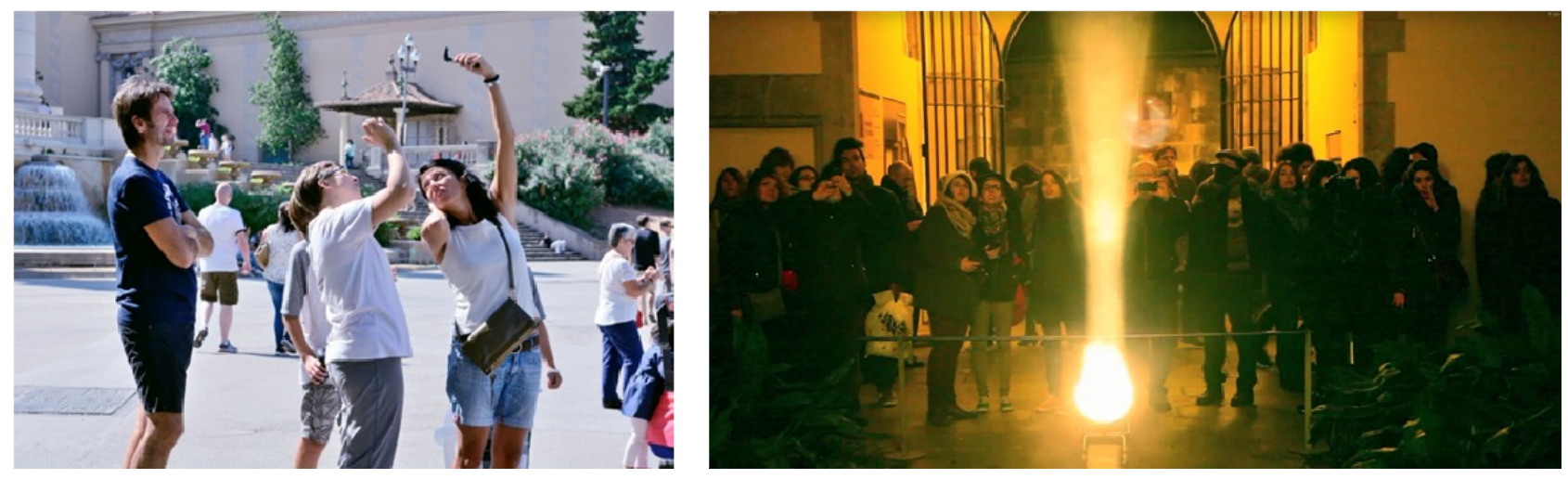

Figure 3: Citizens of Barcelona participating in the citizens science experiment coordinated by ICFO within the LIGHT2015 project and participation of ICFO at the Barcelona's light festival LlumBCN in celebration of the IYL and within the GoPhoton! project

\section{ANALYSIS OF THE SUCCESS}

\subsection{The synergies of the collaborations}

The approach of teaming up with other organizations has resulted in a broadening of the type of activities that each institution offered in comparison to the ones they implemented before the collaboration started. This increase is a result of the sharing and replication strategy followed at ECOP in this GoPhoton! project. As mentioned before, outreach teams are often composed by staff whose primary job might not be outreach per se, and it is therefore important that these teams can access and integrate the knowhow around new outreach activities easily and efficiently. Furthermore, the synergies between partners have led in some cases to new activities that were not foreseen before the start of the project, and have been created through the knowledge transfer and the process of interacting and participating in other partner's activities. A good example would be the Photonics Apps ${ }^{16,17}$, which initially were seen as standalone materials that evolved into an activity that has been integrated in events such as the Open Days.

All partners have added new activities to their range of offered activities and pre-existing activities have been enhanced through the learnings of the collaborations. The fact of being able to experience the events in other settings and by other institutions, has enabled learnings that are difficult to make when one always implements them individually and under the same conditions. Another important point to mention is that sharing the materials has also facilitated enormously the replication part. The creators of the materials prepare it in digital format, so that the layout, illustrations, design and content in English was disseminated among the partners so that each institution only needed to translate the materials into their local language and produce them locally. This has been proven especially effective with the Photonics Exhibition, which was created by ICFO, that sent the posters in electronic version in English to all partners, and these translated them and produced them locally. This has led to the display of the exhibition that since January 2015 can be seen in at least one location, having been displayed in dozens of location across Europe. These posters are also available to everyone in electronic format and in all the languages 
that they were translated into by the partners in the ECOP's website ${ }^{18}$, so that this outreach material can be replicated even more across Europe and beyond.

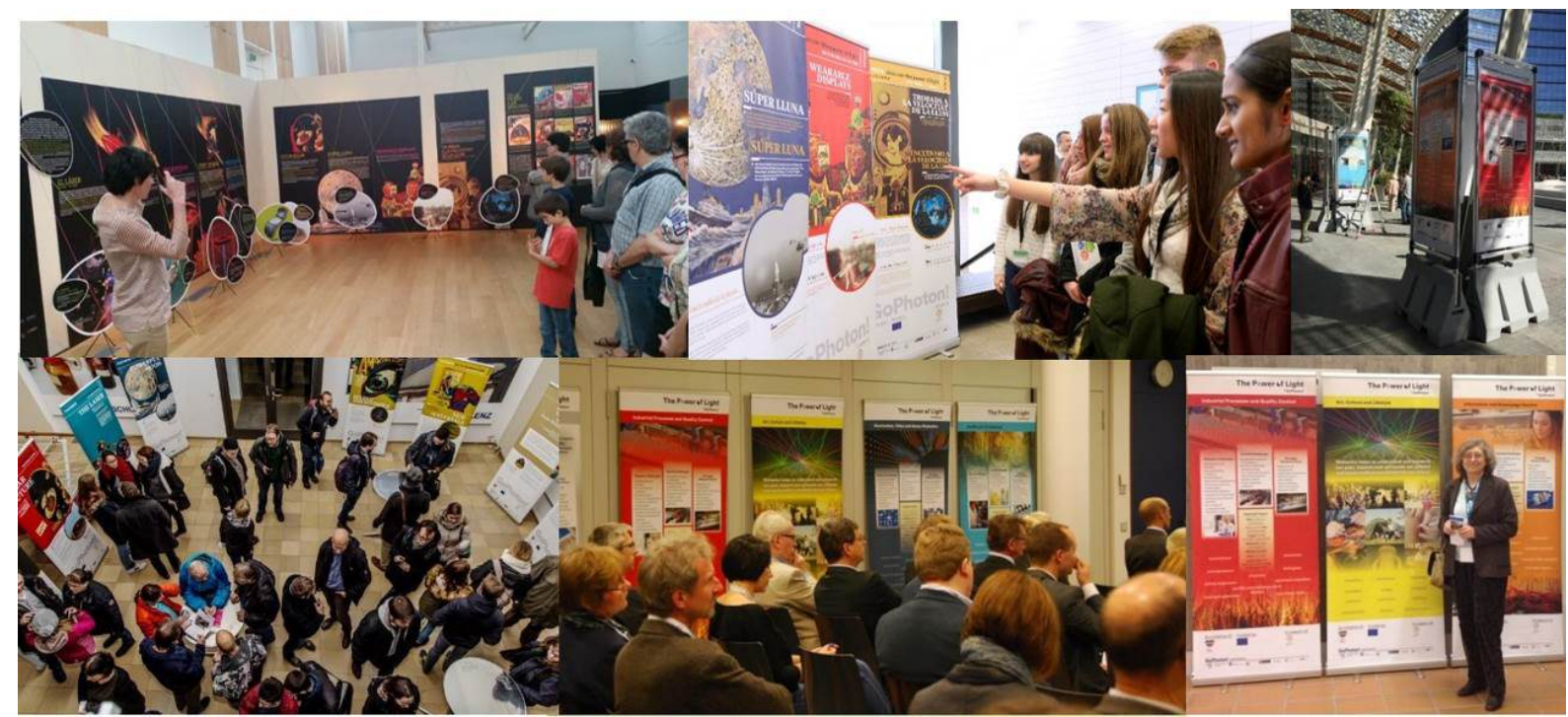

Figure 4: The GoPhoton! Photonics exhibition has been shown since January 2015 in several locations across Europe

\subsection{Number of attendees and impacted people}

The core of GoPhoton! has been the development and replication of activities across the different participating nodes following a structure of collaboration in which sharing and replication of the same activities occurred. To maximize the visibility and impact of the activities, these were organized in "Photonic Splashes", defined as periods of intense photonics outreach. During the period of time in which GoPhoton! activities happen (14 months), over 200 different activities were organized by the ECOP partners, which were attended by almost half a million people.

The way the impact was measured followed a defined methodology of considering the number of people that attended the events and the appearances of the event in different communications channels, since it is considered that the impact goes beyond the attendance of the meetings. Thus, when talking about impact, it is defined as the number of people/organizations that have received the message that has been communicated through the activity, either directly by attending the event or indirectly through other channels such the appearance in media, websites, twitter, etc. However, it is unrealistic to think that the entire audience of a TV program where an event has been conveyed has been effectively listening and integrating the message. It is for that reason that in order to estimate what this impact is, the ECOP partners used a consistent methodology that everyone used to calculate the number of people that have been impacted by the different activities through the different channels.

Using this methodology, it has been estimated that over two million people have been impacted by the GoPhoton! activities, helping to make Photonics a household word. This impact has only taken into consideration the attendance and the communications channels for which information was available. It does not take into consideration the indirect impact that happens through the attendance. For instance, it is reasonable to think that many of the school teachers who attended the organized workshops, are integrating the learnings in their classrooms, impacting thousands of children that have not 
been accounted for. To do it would have required to put in place a follow up mechanism that unfortunately was not possible given the available resources.

\section{DISCUSSION AND CONCLUSIONS}

There are reports that point out the need to change the way science is communicated ${ }^{19,20,21}$, indicating that outreach activities have also to be innovative and adapt to the $21^{\text {st }}$ century. Traditional talks and guided tours are not sufficient anymore to attract and engage students, entrepreneurs, educators, general public, etc. Institutions need to innovate and create new ways to communicate with all different audiences. This is a major project and it entails human and financial resources that are often insufficient in the area of outreach. In order to approach this challenge, collaborating with other research institutions to share not just knowhow but also material and content is proving to be resourceful. Of course there are still financial requirements in order to implement the activities, but this initial sharing among research organizations active in photonics outreach is an effective way to get to fresh new ideas. Furthermore, collaborations have also proven to be valuable in the generation of new, innovative activities, especially when local organizations and professionals team up together, as seen in multidisciplinary activities such the contest Light on the Waves ${ }^{7,8}$, which requires a tight collaboration with professionals of the literature, music and education areas. This contest was created by ICFO and replicated by other institutions. In other words, we believe that outreach in general and Photonics outreach in particular has a great opportunity to innovate through collaborations, both internationally and locally and between research institutions as well as with institutions, organizations and professionals from other disciplines as seen with the success of the GoPhoton! Project.

\section{ACKNOWLEDGMENTS}

We thank all the members of ICFO and the ECOP partners who have provided valuable help on the content and organization of our outreach activities. This work has been partially supported by the Severo Ochoa Excellence Programme, the Fundació Privada Cellex, the Fundació Mir-Puig and the Fundació Catalunya-LaPedrera. GoPhoton! has received funding from the European Union's Seventh Framework Programme for research, technological development and demonstration under grant agreement no 619635, and LIGHT2015 from the European Union's Horizon 2020 research and innovation programme under grant agreement No 644964.

\section{REFERENCES}

[1] United Nations General assembly, "Resolution adopted by the General Assembly on 20 December 2013" https://documents-dds-ny.un.org/doc/UNDOC/GEN/N13/452/71/pdf/N1345271.pdf?OpenElement, UN (2014)

[2] Wieman, C., "Science Education in the 21st Century. Using the Tools of Science to Teach Science.". University of British Columbia and University of Colorado, Boulder, https://net.educause.edu/ir/library/pdf/ff0814s.pdf (2008)

[3] ECOP, "GoPhoton - Photonics for all" http://www.gophoton.eu, ECOP (2015)

[4] LIGHT2015, “The International Year of Light in Europe 2015” http://www.europe.light2015.org/, LIGHT2015 (2015) 
[5] Ferdinand-Braun-Institut, "Mädchen-Technik-Kongress"

http://www.adlershof.de/termin/event/detail/09/10/2015/maedchen-technik-kongress/, FBH (2015)

[6] B-Phot, "B-PHOT-s-interactive-photonics-show-welcomes-more-than-1000-pupils" http://www.b-

phot.org/www/News/B-PHOT-s-interactive-photonics-show-welcomes-more-than-1000-pupils”, B-Phot (2014)

[7] García-Matos, M., Carrasco, S., "Light on the Waves: Science, music, poetry... and light!", Proc. SPIE 9289, 12th Education and Training in Optics and Photonics Conference, 92892E (July 17, 2014); doi:10.1117/12.2070733

[8] ICFO, "La llum a les ones" www.lallumalesones.icfo.eu, ICFO (2012)

[9] Florensa, C., Martí, M., Chaitanya Kumar, S.K., Carrasco, S., "The magic of light! An entertaining optics and photonics awareness program", Proc. SPIE 9289, 12th Education and Training in Optics and Photonics Conference, 92892J (17 July 2014); doi: 10.1117/12.2070738

[10] Chappel, A., “Light matter" http://www.andrewchappel.com, Andrew Chappel (2015)

[11] Fundacio Sabadell 1859, "Exposició 'Pull\&Push: Un món empès per la llum” http://www.petitsabadell.cat/24533097-exposicio_pullpush_un_mon_emps_per_la_llum, Fundacio Sabadell 1859 (2015)

[12] Lightecture, "Un recorrido por el festival LLUM BCN 2015" http://www.lightecture.com/un-recorrido-por-elfestival-llum-bcn-2015/, Lightecture (2015)

[13] Ajuntament de Barcelona, "Llum BCN 2016" http://lameva.barcelona.cat/santaeulalia/llumbcn, Ajuntament de Barcelona (2016)

[14] ICFO, “BCN-Respira” http://bcn-respira.icfo.eu/, ICFO (2015)

[15] BCN Lab, “Oficina de Ciència Ciutadana” http://www.barcelonalab.cat/ca/projectes/cciutadana/, BCN Lab (2015)

[16] ECOP, "GoPhoton! App Coulours" https://play.google.com/store/apps/details?id=eu.gophoton.colours, ECOP (2015)

[17] ECOP, "GoPhoton! App Heartrate“ https://play.google.com/store/apps/details?id=eu.gophoton.heartrate, ECOP (2015)

[18] ECOP, "Download promotional and outreach activities" http://ecopalliance.eu, ECOP (2016)

[19] Donovan, M.S., "Generating Improvement Through Research and Development in Education Systems" Science, Vol. 340, Issue 6130, 317-319 (2013)

[20] Feinstein,N.W., Allen, S., Jenkins, E., "Outside the Pipeline: Reimagining Science Education for Nonscientists" Science, Vol. 340, Issue 6130, 314-317 (2013)

[21] de Jong, T., Linn, M.C., Zacharia, Z.C., "Physical and Virtual Laboratories in Science and Engineering Education" Science, Vol. 340, Issue 6130, 305-308 (2013) 